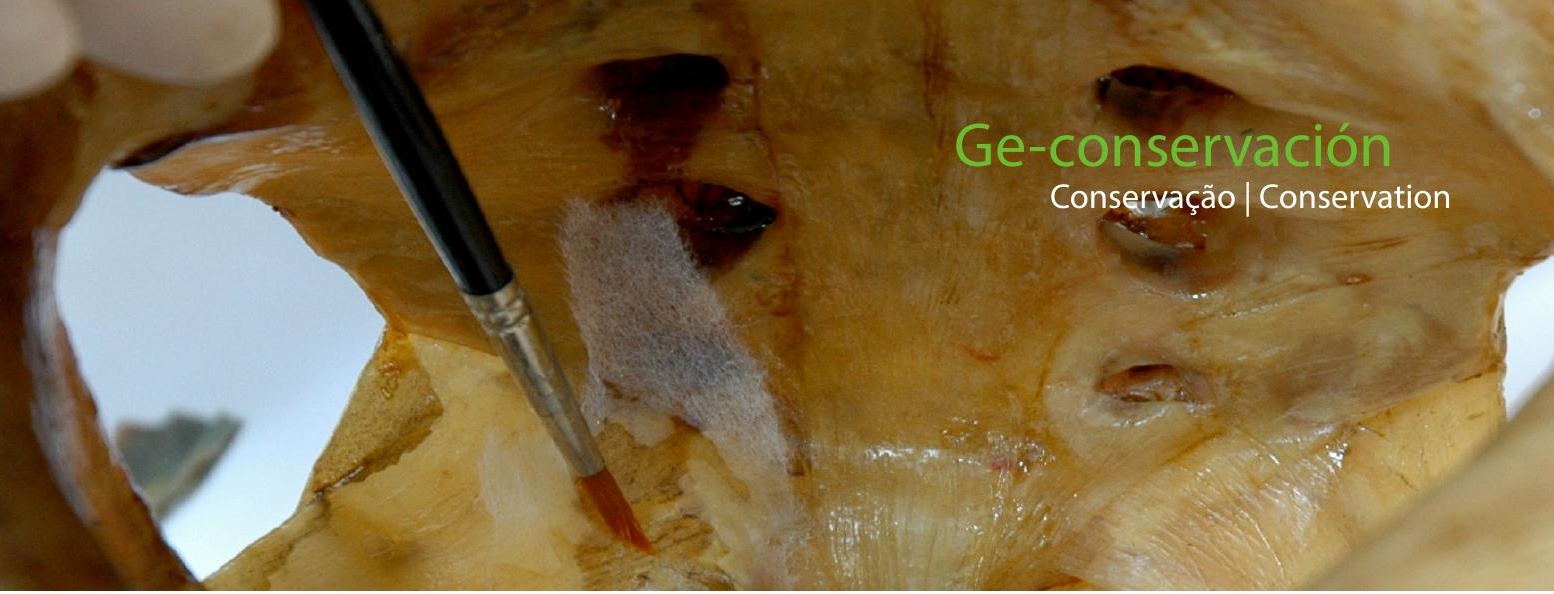

\title{
Restauración de modelos anatómicos en cera: Colección del Real Colegio de Cirugía de San Carlos.
}

\begin{abstract}
Alicia Sánchez Ortiz
Resumen: La anatomía en cera se desarrolló a partir del arte renacentista al encontrar la dilatada praxis de taller un nuevo campo de expresión plástica dentro de la enseñanza médica. Dicho material fue altamente valorado por su utilidad para trasladar al artefacto inanimado todos los detalles morfológicos del cuerpo muerto. Este artículo analiza la problemática de conservación-restauración de modelos anatómicos de cera en colecciones médicas. Se ofrece una revisión ordenada de la literatura científica específica sobre este tipo de actuaciones en ceroplástica, dedicando un especial interés a dos de las fases más complejas: la adhesión de fragmentos y los sistemas de limpieza. Se exponen los tratamientos de restauración efectuados en algunas piezas existentes en la colección del Museo de anatomía "Javier Puerta" de la Facultad de Medicina de la Universidad Complutense, con motivo de su préstamo para una exposición temporal.
\end{abstract}

Palabras clave: cera - modelos anatómicos - colecciones médicas - conservación- restauración.

\section{Restoration of anatomical wax models: Collection of the Royal College of surgery of Saint Charles}

Abstract: Wax anatomy developed from Renaissance art to find, for the long practice of the workshop, a new field of artistic expression within the medical education. This material was highly valued for its utility of moving to the inanimate artifact all the dead body's morphological details. This article analyzes the conservation and restoration problems of anatomical wax models in medical collections. It's offered a literature orderly review about this type of methods on ceroplastic, giving a special attention of two of the most complex phases: the accession of fragments and cleaning systems. The proposed treatment is in connection with the restoration of some pieces in the collection "Javier Puerta", Anatomy Museum of the Medicine Faculty, Complutense University, on his loan to be exposed on a temporary exhibition.

Key words: wax - anatomical models - medical collections - conservation and restoration.

\section{Restauro de modelos anatómicos em cera: Coleção do Real Colégio de Cirurgia de San Carlos}

Resumo: Resumo: A anatomia em cera desenvolveu-se a partir da arte renascentista, tendo esta antiga prática oficinal encontrado um novo campo de expressão plástica dentro do ensino médico. Este material foi altamente valorizado pela sua utilidade em transferir para o artefacto inanimado todos os detalhes morfológicos do corpo morto. Este artigo analisa a problemática de conservação e restauro de modelos anatómicos de cera em coleções médicas. Apresenta-se uma revisão ordenada da literatura científica específica sobre este tipo de operações ceroplásticas, dedicando um interesse especial a duas das fases mais complexas: a adesão de fragmentos e os sistemas de limpeza. Expôem-se os tratamentos de restauro efetuados em algumas peças existentes na coleção do Museu de anatomia "Javier Puerta" da Faculdade de Medicina da Universidade Complutense, a propósito do seu empréstimo para uma exposição temporal.

Palavras-chave: cera, modelos anatómicos, coleções médicas, conservação e restauro. 


\section{Introducción}

La cera, capaz de adaptarse a la perfección para reproducir el más mínimo detalle anatómico del cuerpo humano, fue elegida por los artistas del Renacimiento para la elaboración de bocetos que servían como herramientas de apoyo a la hora de plantear escorzos o valorar los juegos de luz en sus composiciones. Este tipo de trabajos pronto atrajo la mirada de los anatomistas y se produjo una estrecha colaboración entre ambos campos del saber (Haviland y Parish 1970: 234). Los modelos artificiales de cera adquirieron su máxima difusión durante el siglo XVIII con el desarrollo de la educación médica. La representación plástica en tres dimensiones, dotada de un elevado grado de realismo, se convirtió en óptima sustituta del cadáver como elemento didáctico y surgieron así numerosas colecciones dentro de los gabinetes anatómicos de los principales colegios de cirugía que, con el tiempo, pasaron a formar parte de los museos universitarios en las actuales facultades de medicina, tanto en Europa como en América.

El Museo de Anatomía "Javier Puerta" de la Universidad Complutense de Madrid es un buen ejemplo de ello. Heredero del gabinete creado en el Real Colegio de Cirugía de San Carlos, a finales del siglo XVIII, atesora una colección única en España, representativa del arte de la ceroplástica. Las piezas más antiguas se hicieron bajo la dirección de Ignacio Lacaba, maestro disector de la institución, y son exponentes de la primorosa habilidad técnica del escultor malagueño de la corte, Juan Cháez, y del modelador de cera toscano, Luigi Franceschi.

\section{Objetivos}

El presente artículo tiene por objeto mostrar el proceso de restauración realizado en cuarenta esculturas pertenecientes al citado museo universitario, con motivo del préstamo de las mismas para la exposición temporal "Cuerpos en Cera. El Arte de la Anatomía", celebrada en el Museo de la Evolución Humana de Burgos bajo el comisariado del profesor Juan Luis Arsuaga, entre abril y junio de 2014. Los resultados que se describen son derivados de la investigación previa a la intervención, llevada a cabo por un amplio equipo interdisciplinar dentro del marco del Proyecto I+D financiado por el Ministerio de Ciencia e Innovación, con referencia HAR2009-10679. En ella se abordaron la búsqueda de fuentes documentales y los estudios relativos al conocimiento de los materiales constitutivos y de las técnicas originales empleadas, mediante un completo análisis de laboratorio. La información obtenida permitió, además, comprender los procesos de degradación y ayudó a establecer las actuaciones más adecuadas para la estabilización y preservación del conjunto.

\section{Restauración de ceras según la literatura científica}

En los últimos años se ha asistido a un reconocimiento del enorme valor artístico de este tipo de objetos y ello ha hecho que creciese el interés por su conservación con la puesta a punto técnicas específicas. Dos han sido las principales líneas desarrolladas: una centrada en el estudio de adhesivos y pastas de relleno, y otra en los sistemas de limpieza.

\section{A.- Adhesión de fragmentos}

Algunas características de la cera, como son su mala humectabilidad, su baja polaridad y su lisura en superficie, determinan unas condiciones desfavorables para la adhesión de fragmentos. Su elevada sensibilidad al calor o a los disolventes condiciona y limita la elección del restaurador, ya que muchos de los adhesivos se aplican en caliente o van preparados en soluciones. A ello se suma la dificultad para lograr una óptima adhesión por contacto manteniendo sujetas las piezas, al ser complicado ejercer una presión sobre la zona a unir, de forma segura. El estudio bibliográfico sobre las prácticas existentes en restauración de objetos céreos, ha puesto en evidencia el uso de una amplia gama de adhesivos.

\section{-1. Adhesivos naturales}

Tradicionalmente, se ha recurrido al mismo material -esto es la cera-, al mostrar un comportamiento mecánico similar. Dado que la fuerza adhesiva de esta sustancia depende de la proporción de propóleos contenidos en ella, el vínculo más fuerte se consigue con cera de abejas pura. En 1976, Jaromir Bacilek propuso tratar pequeñas micro-fisuras o escamas en sellos con una solución entre el 1,5 - 2\% de propóleo en etanol (95\%); pero desaconsejaba su uso en caso de tener como componentes resinas naturales, tipo colofonia o goma laca, ya que podría dañarlos (Dernovskova 1997: 12 y 14; Reifarth 2004).

La cola animal ha sido empleada para consolidar y adherir capas pictóricas a la encáustica y también altorrelieves en cera, combinando cola de conejo y cola de pescado (Filipp 1998: 58). Ésta muestra una sorprendente fuerza adhesiva, una adecuada humectación de la superficie teniendo en cuenta su naturaleza hidrófila (Fischer and Eska 2011: 3-5), además de garantizar una óptima reversibilidad (Lang 2011: 13). La cola de esturión purificada, al 5\% en agua desmineralizada, se usa en restauración de sellos por su buena resistencia mecánica a la flexión, apropiada capacidad de humectación y correcta fuerza adhesiva.

\section{-2. Adhesivos sintéticos}

Con una aplicación reciente en ceroplástica, las resinas sintéticas ofrecen resultados satisfactorios debido a su poder de adhesión, su diferenciación de la materia original y, en algunos casos, su estabilidad en el tiempo. Autores alemanes hacen referencia al polietilenglicol, PEG 6000 disuelto en etanol, como adhesivo y consolidante para la restaura- 
ción de objetos en cera (Reifarth 2003: 51 y 2004: 118). El PEG puede también ir en agua pero tiene una mala humectación en la superficie cérea y una escasa fuerza adhesiva (Lang 2011: 10); este producto muestra cierta sensibilidad ante fenómenos de oxidación térmica y fotoquímica.

Otra opción para no provocar una posible hinchazón en las partes a unir, consiste en elegir polímeros naturales y sintéticos. Un buen mojado de la superficie se considera esencial para conseguir una adherencia correcta. En este sentido, se han utilizado con éxito emulsiones de adhesivos para reparar pequeñas fracturas (Murrell 1971: 105; Kaufmann 1988: 29).

Una de las resinas sintéticas más citadas en los estudios es el acetato de polivinilo (PVA) (Besnainou 1984: 56; Chicoineau 2001: 30; Lang 2011: 10; Pradier 2011: 93). La mayoría lo emplean en medio acuoso y en frío, si bien Dal Forno (2009: 82 y 83) recomienda disolverlo con alcohol y aplicarlo en caliente con pincel y cita el Vinamul ${ }^{\circledR} 525$ para piezas de mayor peso. En el tratamiento de grietas se señala un adhesivo de base acuosa como el Evacon- $\mathrm{R}^{\circledR}$, un copolímero de acetato de etilvinilo en emulsión. Es menos susceptible a la hidrólisis ácida que el resto de los PVA, los cuales pueden emitir vapores de ácido acético. Tiene un $\mathrm{pH}$ neutro. Dado el prolongado tiempo de secado del mismo, es necesario mantener los fragmentos a unir sujetos de forma provisional con cintas durante la operación de adhesión de las partes dañadas a fin de conseguir un encolado óptimo (Gramtorp et al. 2013: 9). El Jade 403N ${ }^{\circledR}$, utilizado en el campo de la conservación para reparar desgarros en lienzos, madera, plástico o cerámica, también ofrece buenos resultados (Ellis et al. 1996: 43). Entre sus principales características destacan: $\mathrm{pH}$ neutro, fraguado relativamente rápido y comportamiento flexible (Lapkin et al. 2002: 97).

En el grupo de las emulsiones acuosas vinílicas se incluye el Mowilith $\mathrm{DMC} 2^{\circledR}$, dispersión de un copolímero de acetato de vinilo y ácido maleico dibutil éster (Champagnac 2002: 143-245), aunque algunas pruebas experimentales llevadas a cabo con Mowilith $30^{\circledR}$ disuelto en etanol mostraron mejor comportamiento en cuanto al poder de adhesión (Fischer and Eska 2011: 8). Preparado en una solución de etanol-agua es menos probable que cause daños a la cera; además, si el objeto tiene una superficie delicada por su estado de conservación, el rápido tiempo de secado del Mowilith $30^{\circledR}$ puede ser una ventaja. Su inconveniente principal deriva de su reversibilidad por vía mecánica o con disolvente, y sus consecuentes riesgos para el original (Land 2011: 12).

Otros investigadores recomiendan el polivinil butiral (PVB), compuesto químico resultante de mezclar el alcohol de polivinilo con el butiraldehído. En concreto, indican el Pioloform ${ }^{\circledR} \mathrm{BM} 18$ disuelto en etanol a diferentes concentraciones (Champagnac 2002: 143-245; Legendre 2011: 111; Pradier 2011: 132) para la adhesión de pequeños fragmentos. La temperatura de transición vítrea de este adhesivo, 70 $C$, garantiza una unión resistente a temperatura ambiente.
Al tener un peso molecular elevado, es bastante viscoso, lo que facilita su aplicación sobre la obra. Tras la evaporación del disolvente, forma una película muy flexible.

Cuestiones a valorar si se opta por los adhesivos acrílicos en disolventes son: si el medio en el que va preparada la resina puede afectar o alterar la superficie del objeto de cera, así como el tiempo de evaporación, ya que si es muy rápido impedirá una correcta humectación de las superficies fracturadas (Lang 2011: 12). Uno de los más recomendados para este tipo de obras es el Degalan ${ }^{\circledR} \mathrm{PQ} 611$, al 40-60\% en White Spirit (Fischer 2011: 4 y 5), y el Paraloid ${ }^{\circledR}$ B72 (Filipp 1998: 47).

Entre las dispersiones acrílicas destacan el Lascaux ${ }^{\circledR} 498 \mathrm{HV}$ y el $360 \mathrm{HV}$, un compuesto a base de éster del ácido butilacrílico espesado con ácido de poli-metacrilato. Como principales características cabe señalar su pH entre 8-9 y una temperatura de transición vítrea de $+13^{\circ} \mathrm{C}$ aprox. Una vez seco, no se observa ningún cambio de color o de brillo sobre la superficie de la cera. Recientemente se ha utilizado en el tratamiento de unión de fragmentos de cera por su fuerza adhesiva, buenas propiedades de trabajo y transparencia al secar (Lapkin et al. 2002: 97). Como inconvenientes algunos estudios señalan que las uniones tienden a ceder no por la junta restaurada sino por el original circundante. Su lenta velocidad de secado implica el apoyo prolongado de las piezas durante la fase de curado inicial, lo que puede ser un problema por la sensibilidad que muestran las ceras al más mínimo roce. Además, este adhesivo se vuelve insoluble en agua una vez completado su secado (Lang 2011: 13-14).

Si existen grietas de cierta entidad con ligeras pérdidas de materia original, es aconsejable el uso de un adhesivo con capacidad de relleno, como el Lascaux ${ }^{\circledR}$ adhesivo cera 44395, compuesto por una cera micro-cristalina y una resina sintética politerpénica. Una pequeña cantidad de este material se calienta con una espátula metálica y se deja gotear sobre la zona dañada con el cuidado de no fundir la cera original. Este adhesivo, al tener una estructura química muy diferente, facilita la reversibilidad del tratamiento (Gramtorp et al. 2013: 9).

\section{B.- Pastas de relleno para nivelación de lagunas}

Los materiales para efectuar rellenos en pérdidas de diversa entidad deben responder a ciertos criterios. En cuanto a las características mecánicas, el producto debe mostrar una plasticidad y dureza similares a las de la pasta de cera original para evitar contracciones mecánicas cuando los dos entran en contacto. Además, tiene que mantener una buena estabilidad en el tiempo, tanto en lo referente a su coloración durante la exposición a la radiación luminosa como en cuanto a las posibles fluctuaciones ambientales. Su índice de acidez (la) no debe ser muy elevado para no ocasionar interacciones químicas dañinas. Otras cuestiones a tener presentes atañen a la manejabilidad que aquél 
debe tener durante su puesta en obra: permitir tanto el trabajo por colada en un molde como a través del modelado, poseer un secado no demasiado rápido para que así el tiempo de manipulación sea lo suficientemente largo como para permitir su colocación con la forma deseada, y disponer de un comportamiento estable y sin retracción durante la fase de curado.

De modo tradicional, se ha utilizado una pasta compuesta por cera de abejas pura o mezclada con cera blanqueada, pero no es recomendable su empleo ya que envejece mal con la aparición de manchas blancas por la hidrólisis de algunos compuestos (Pradier 2011: 94). Se puede recurrir a la combinación de ambas ceras y adicionar blanco de ballena o cera espermaceti para bajar el punto de fusión de la mezcla y asegurar la reversibilidad (Chicoineau 2001: 30). Ceras vegetales -como la carnauba-, se usan junto con la cera de abejas para modificar determinadas propiedades de ésta última, en concreto aumentar la dureza de la pasta y subir su temperatura de transición vítrea (Tg) (Delcroix et al. 2005: 11; Murrell 1971:101). Esto permite obtener un material de relleno más resistente a las condiciones de conservación y menos susceptible de atraer el polvo (Legendre 2001: 21). Hückel y Schnell (1987: 155), Kaufmann (1988: 29) y Fischer (2011: 2) consideran que la resina dammar puede mejorar la resistencia del adhesivo, aunque no se recomienda optar por esta solución ya que los componentes tienden a separarse durante su envejecimiento natural.

En cuanto a la metodología de aplicación, lo más común ha sido recurrir al calor durante el proceso de recomposición de la pieza fragmentada, bien mediante la incorporación de una masilla de cera líquida caliente o con la ayuda de una espátula térmica; pero esto puede alterar la estructura del sustrato céreo original circundante y ocasionar posibles deformaciones o decoloraciones en la pasta. La cera de abejas tiene una temperatura de fusión elevada, entre $60-65^{\circ} \mathrm{C}$. Para evitar estos riesgos, algunos prefieren aplicar la pasta de relleno en solución con disolventes orgánicos no polares (Kühn 2001: 314); este método tiene también inconvenientes pues conlleva una alta retención de los mismos y puede causar una hinchazón, más o menos profunda, en los bordes de la rotura.

Las ceras minerales micro-cristalinas son apreciadas por su inercia química y su óptima estabilidad. Una de sus principales ventajas es la posibilidad de ser mezcladas entre ellas o con otras ceras naturales -como la de abejas-, para aumentar su temperatura de transición vítrea ( $\mathrm{Tg}$ ) (Delcroix et al. 2005: 17). Otra opción consiste en recurrir a combinaciones de cera micro-cristalina y resinas sintéticas, por ejemplo Lascaux ${ }^{\circledR}$ 443-95 y la resina Kremer $^{\circledR}$ 62620 (Hückel and Schnell 1987: 155; Buschendorf 1995: 48; Filipp 1998: 43), con lo que se consigue dotar a la pasta obtenida de una adecuada fuerza adhesiva y cierta flexibilidad. Las ceras micro-cristalinas son más duras y resistentes a las variaciones climáticas, y menos transparentes que las parafinas; muestran una mínima contracción al solidificar y son neutras. La cera micro-cristalina, tipo Cosmolloid $^{\circledR}$, puede mezclarse con la cera mineral, Parafina 50-52, para obtener una pasta con un comportamiento mecánico y químico bastante bueno (Pradier 2011: 116); al tener una consistencia similar a la plastilina, es adecuada para ser manipulada con las manos. En el comercio existen diversos tipos de parafinas que se diferencian entre sí por el punto de fusión. Todas son transparentes, se pueden teñir con facilidad $y$, al ser neutras $(l a=0)$, no crean interacción con el resto de otros materiales. En el OPD de Florencia, el material más utilizado es la Parafina 774 (Gabbriellini et al. 2008: 230 y 233; Cordua et al. 2009: 48 y 49), preferida a otras ceras de origen animal o vegetal por su particular estabilidad química y su ausencia de impurezas.

\section{C.- Estudios relativos a los procesos de limpieza}

Una de las principales dificultades a superar por el restaurador durante la operación de limpieza en un objeto de cera es ocasionada por la capacidad termoplástica del propio material, lo que contribuye a atrapar las partículas de polvo cuando se produce un reblandecimiento de su superficie como respuesta a un aumento de temperatura ambiental, quedando englobadas y formando cuerpo con ella cuando descienden de nuevo los valores térmicos. Es esencial que aquél llegué a una situación de compromiso con la obra y evalué la idea de una posible desigualdad en el grado de limpieza a alcanzar.

Los cambios químicos de los materiales que componen la pasta cerosa influyen en la sensibilidad que ésta mostrará frente a los diferentes productos de limpieza. Si la cera de abejas está envejecida, los hidrocarburos se caracterizan por una pérdida de moléculas de bajo peso molecular y los ésteres estarán hidrolizados, lo que entraña la formación tanto de alcoholes como de ácido palmítico, con un aumento de su acidez.

Otra variable que debe tenerse en cuenta es la morfología de la superficie del objeto sobre el que se va a efectuar el tratamiento de limpieza. Una superficie con falta de cohesión en los estratos y alterada por la presencia de componentes migrados, representará, sin duda, un factor de riesgo intrínseco para la obra.

Cualquier producto a emplear en esta operación tiene que cumplir con una serie de criterios generales. En lo referente a la inocuidad para el material original, la sustancia limpiadora no debe solubilizar la cera original ni entrañar la aparición de blanqueamientos sobre su superficie. Es preciso prestar mucha atención con el fin de no dañar las veladuras pigmentadas ya que era habitual en los talleres realizar refinamientos estéticos finales con barniz transparente, sandáraca, o goma laca.

Una primera fase consiste en la limpieza en seco con un cepillo de pelo suave o/y un flujo de aire para eliminar las 
partículas sólidas y el polvo suelto depositado sobre la superficie de la escultura (Gramtorp et al. 2013: 6). A continuación, suele ser necesaria una limpieza por vía húmeda con la ayuda de un pincel suave, o el empleo de pinceles de pelo de marta e hisopos de algodón, ligeramente humedecidos, para la casi totalidad de los tratamientos con soluciones acuosas o disolventes, así como su posterior enjuagado y secado (Murrell 1971: 100 y 101; Künh 1986: 131; Champagnac 2002: 64; Pradier 2011: 123; Gramtorp et al. 2013: 9). Factores a valorar son el tiempo de contacto del producto seleccionado sobre la superficie cérea y el modo de manipulación del instrumental. Se recomienda que el proceso sea lo más rápido posible, de no más de unos segundos, y se señala la conveniencia de dejar evaporar por completo el disolvente antes de proceder a una nueva aplicación (Murrell 1971: 101). Es imprescindible evitar la frotación a fin de no provocar huellas o eliminar detalles del modelado original (Kühn 1986: 131). Para conseguir una limpieza más suave se pueden usar tisúes absorbentes o compresas hechas con productos tixotrópicos, de modo que se reduzcan los riesgos derivados de la acción mecánica (Gabbriellini et al. 2009: 37). El gel se aplicará con un pincel sobre una hoja de papel situado en la zona a limpiar para evitar que el medio húmedo pueda ocasionar la formación de pasmados.

\section{-1. Tensoactivos}

El ambiente acuoso está considerado uno de los tratamientos más adecuados para la eliminación de suciedad superficial. Al modificar ciertos parámetros, como el valor de $\mathrm{pH}$ o la concentración iónica de la solución, se consigue minimizar el riesgo de interacción con las sustancias filmógenas (Berzioli et al. 2010: 21). La mayoría de los autores aconsejan utilizar tensoactivos no iónicos, Lissapol ${ }^{\circledR}$ al 2\% (Murrell, 1971: 100), Saponina, con un pH 4,7 (Chicoineau 1989: 24), y Tween ${ }^{\circledR} 20$ al 2-5\% (Gabbriellini et al. 2009: 36; Pradier 2011: 122-127), o aniónicos, Howards ${ }^{\circledR}$ B30 al 3\%-10\% (Murrell 1971: 100) o Orvus ${ }^{\circledR}$ al 0,5\% w/v (Ellis et al. 1996: 44), en agua desionizada o destilada. Para mejorar el bañado de la superficie cérea por parte de las soluciones acuosas se incorpora un gel espesante, neutro, con carácter pseudo-plástico, como la goma Xantano, Vanzan $^{\oplus}$ NF-C hasta un 1,5\% (w/v) (Berzioli et al. 2010: 24). Tras la aplicación de la solución gelificada se procede a la retirada en seco del gel y a lavados con hisopos humedecidos en agua para retirar posibles residuos. Si se usan soluciones acuosas con pH ácido, inferior al pka de los ácidos grasos de la pasta de cera, se consigue minimizar la ionización de los mismos dado que conservan un carácter hidrófobo y resultan prácticamente insolubles en el medio acuoso (Berzioli et al. 2010: 42).

\section{-2. Disolventes orgánicos}

Una de las primeras consideraciones a tener presente es, como ya se ha indicado, el carácter termoplástico de la cera. Esta propiedad dificulta enormemente la separación entre el material de depósito y la superficie de la pieza, dado que la propia plasticidad de aquélla lleva a una progresiva incorporación de las partículas de polvo en el interior de la pasta, formando una especie de estrato pigmentado. Puede ocurrir que con el tiempo, la escultura haya sido re-barnizada en diferentes momentos históricos, lo que todavía contribuye más a su transformación estética.

Se tratará, por tanto, de aligerar suavemente los barnices añadidos sin disolver la cera original ni perder detalles de la superficie. La elección del producto viene determinada por algunos requerimientos. En primer lugar, el disolvente debe ser completamente volátil, con una rápida evaporación acorde al método de aplicación elegido. Dicha sustancia tiene que ser inocua para la materia original y tener una baja o nula toxicidad. Conviene realizar una serie de test en zonas poco comprometidas de la pieza para determinar el disolvente más eficaz, pudiendo ser también de ayuda el Triángulo de Solubilidad de Teas. Se debe limpiar $\mathrm{cm}$ a cm y si es necesario repetir la operación, siempre dejando que la cera recupere su dureza inicial. Es esencial optar por un tipo de disolvente orgánico que tenga una adecuada polaridad: los apolares o poco polares, tendrán la capacidad de disolver la cera; los de media polaridad, como los ésteres, podrían interactuar con los compuestos un poco más polares presentes en la cera, como los ácidos grasos y los alcoholes grasos, en grado suficiente como para provocar un fenómeno de lixiviación; por último, los disolventes polares no la afectarían. En el pasado se han empleado el cloroformo (Chicoineau 1989: 23; 2001: 30), a pesar de mencionarse su alta toxicidad, hidrocarburos aromáticos, como tolueno, xileno o nafta, o hidrocarburos alifáticos, como White Spirit o Shellsol ${ }^{\circledR}$ T. La cera de abejas muestra una elevada sensibilidad a todos ellos al provocar en su superficie reblandecimiento y matificado (Murrell 1971: 101; Chicoineau 1989: 25). El alcohol más recomendado es el isopropílico y el etanol (Besnainou 1984: 53; Champagnac 2002: 117; Dal Forno 2009: 82 y 89; Pradier 2011: 124-127), aunque con riesgo de que aparezcan ligeros brillos (Chicoineau 1989: 24).

\section{Caso de estudio: Modelos en cera del Museo de Ana- tomía "Javier Puerta" (Universidad Complutense de Madrid)}

\section{Objetivo de la intervención}

Como se ha citado con anterioridad, la exposición temporal "Cuerpos en cera. El arte de la anatomía a la luz de la Razón", permitió abordar un proyecto de conservación y restauración sobre cuarenta modelos anatómicos en cera, patrimonio de la Universidad Complutense de Madrid, cuyo principal objetivo fue contribuir a la puesta en valor de una colección singular y única en nuestro país. La intervención ha posibilitado garantizar la estabilidad material de las obras y ha contribuido a mostrar al visitante la selección de los modelos artificiales en cera con la enorme 
riqueza de detalles formales y anatómicos más próximos a la intención original de sus artífices.

\section{Metodología de restauración}

Con el fin de cumplir con los objetivos referidos, se llevó a cabo una primera fase consistente en la recopilación y revisión historiográfica de las fuentes de archivo. A continuación, cada escultura fue sometida a una exhaustiva inspección visual con ayuda de microscopio estereoscópico y se procedió tanto a su documentación fotográfica con diferentes iluminaciones (luz difusa, polarizada, transiluminación, ultravioleta y rasante), como a la elaboración de cartografías que recogiesen las principales alteraciones existentes. Algunos modelos anatómicos fueron examinados en profundidad con RX y Tomografía axial computerizada (TAC) para determinar las características constructivas en su interior.

En paralelo, se procedió a un estudio pormenorizado de las características y propiedades físico-químicas clasificando a las esculturas por tipologías para disponer de información sobre la naturaleza material, las técnicas de manufactura y el estado de conservación de los materiales. El muestreo abarcó desde las pastas de cera, los pigmentos, el cabello, los metales empleados en las estructuras internas de refuerzo, los hilos impregnados en cera para la recreación de detalles anatómicos, hasta las películas de recubrimiento y los depósitos de suciedad. Las técnicas de análisis empleadas fueron Espectroscopia infrarroja por transformada de Fourier (FTIR), Cromatografía de gases-Espectrometría de masas (GC-MS), Pirolisis, Microscopia electrónica de barrido - Microanálisis por dispersión de energías de RX (SEM-EDX) y Microscopía óptica con luz polarizada. A partir de los datos obtenidos y en función del estado de conservación de cada obra y de cada zona de la misma, se seleccionaron los productos de restauración y se ajustó la metodología de aplicación.

\section{Descripción de las obras}

Los modelos anatómicos sometidos a los tratamientos de restauración son esculturas de bulto redondo huecas, elaboradas con pastas de cera de abejas virgen, a las que los artífices añadieron una resina natural diterpénica, Trementina de Estrasburgo, y una grasa animal, manteca de cerdo, en diversas proporciones, para modificar las propiedades iniciales de aquéllas y hacerlas adecuadas a las exigencias técnicas del proceso creativo. Salvo la figura del esqueleto de mujer, dotada de un alma interna de hierro que soporta la distribución de pesos y aporta estabilidad al conjunto de la obra, el resto de ellas han sido trabajadas con estopa impregnada en cera, lo que permitía ir reforzando las partes más débiles de las juntas entre las extremidades. Se ha comprobado también que las partes principales de cada figura fueron construidas con la ayuda de moldes de yeso y una vez obtenido el positivo en cera, los artistas fueron añadiendo los diversos detalles anatómicos con pastas de cera, teñidas en diferentes tonalidades para ajustarse a la veracidad del espécimen a reproducir.

\section{Estado de conservación}

En general, todas las esculturas estudiadas manifestaban, en mayor o menor grado, un estado similar de deterioro debido a causas afines, ya que han estado expuestas a idénticos agentes de degradación, se encuentran colocadas dentro de vitrinas de época en la misma sala del museo y fueron realizadas con la misma técnica, con similares materiales, por los mismos autores y en el mismo periodo histórico.

Muchos son los factores de degradación que han padecido estas piezas tan singulares y que han contribuido a que se deteriorasen con el tiempo. Aunque la cera posee una buena estabilidad -al estar caracterizada por enlaces covalentes y saturados-, el uso de los modelos artificiales como herramientas de apoyo docente en las aulas, ha favorecido que se dañasen durante su constante manipulación. A ello se suman un cierto abandono provocado por cambios en los sistemas de docencia universitaria y unas condiciones poco adecuadas para su exposición en sala.

El envejecimiento natural unido a un ambiente expositivo con valores de temperatura fluctuantes, son las principales causas de deterioro. Las pastas con las que fueron modeladas las esculturas muestran, en algunos casos, un estado frágil y quebradizo, con un aumento del índice de acidez. Las sustancias grasas (manteca de cerdo y sebo), al envejecer sufren una hidrólisis parcial de los ésteres con la formación de ácido palmítico C17:0 y ácido esteárico C18:0, así como de diglicéridos y monoglicéridos, visibles en la superficie de la cera como una cristalización blancuzca. En la parte de las esculturas que está en contacto directo con armazones metálicos internos -por ejemplo, la figura del esqueleto-, se observan manchas oscuras, de color pardo, debidas a los productos de corrosión por la reacción del hierro y de los ácidos grasos, lo que afecta a la solidez de la pasta.

Todas las figuras presentan una gruesa capa de depósitos de partículas atmosféricas, que altera el característico aspecto traslúcido de la cera y modifica, en mayor o menor medida, las diversas tonalidades cromáticas características de cada parte anatómica. Las propiedades electrostáticas de la cera de abejas hacen que la superficie de los objetos muestre una elevada tendencia a atraer y retener la suciedad. Fenómeno que se ve agravado por las variaciones de temperatura y la respuesta del propio material debido -como ya se ha indicado- a su temperatura de transición vítrea.

En general, el conjunto de las obras estudiadas ofrece unos acabados estéticos muy brillantes, poco acordes con 


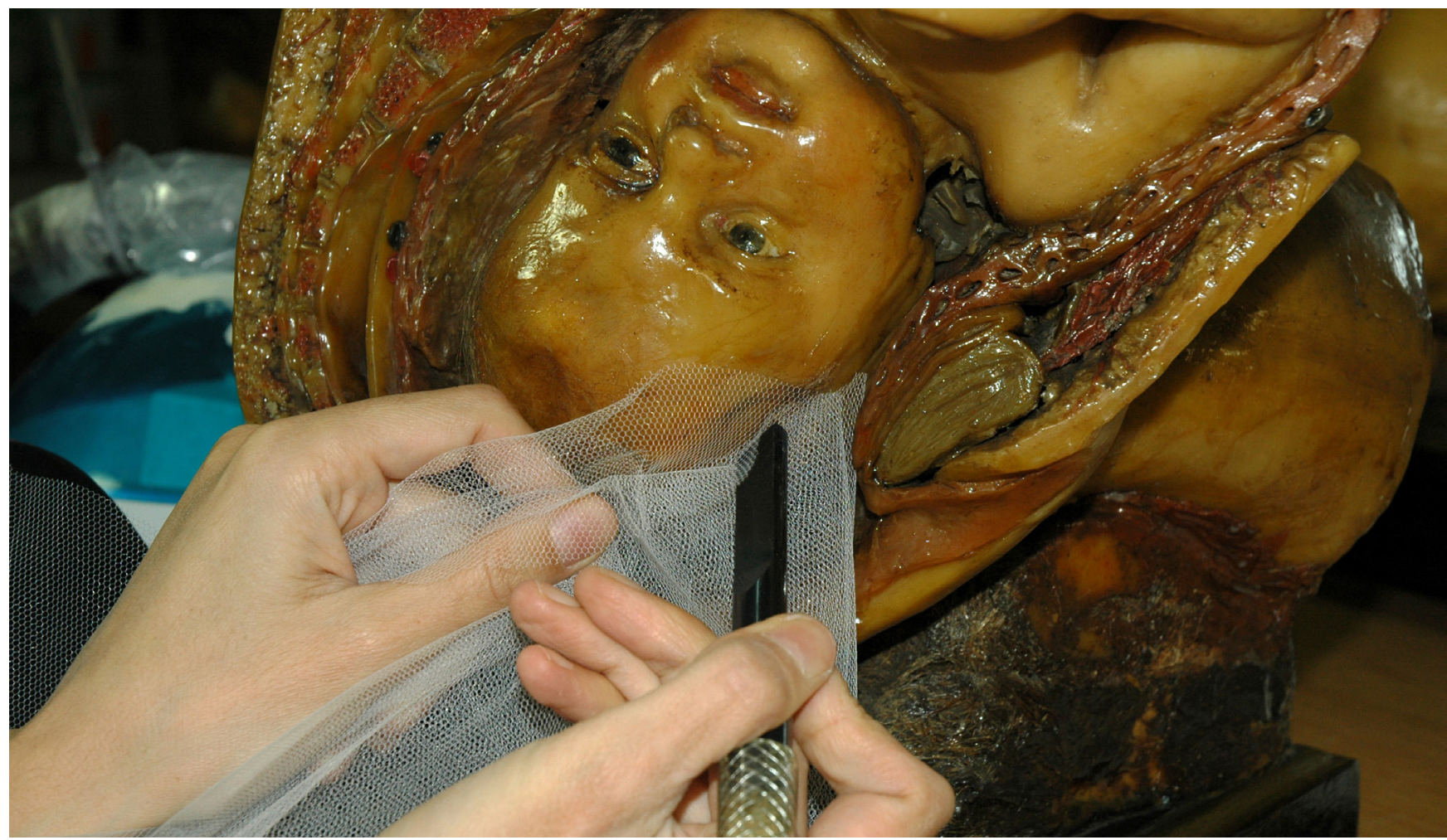

Figura 1. Detalle de la aspiración del polvo depositado en la superficie de la escultura. Embarazo a término, primera rotación (MAJP000146). Cera policromada, cabello humano y madera. 32 × 33 × 48 cm. @ C Alicia Sánchez Ortiz.

la época de creación, al recibir, en diferentes momentos históricos, varias capas de barniz con grosores muy irregulares y escaso cuidado en el proceso técnico. Los análisis químicos han determinado que su composición es una resina natural de tipo terpénico, en concreto colofonia. Estas películas de recubrimiento muestran una fuerte oxidación que se visualiza en una alteración cromática de todos los detalles anatómicos, lo que supone para cada pieza una pérdida de funcionalidad y una merma considerable de su valor artístico.

Algunas partes de las esculturas tienen micro-fisuras y fracturas con pérdida de materia original como consecuencia directa de accidentales fortuitos ocurridos durante el traslado de las mismas por cambio de su ubicación original o por el uso didáctico que tuvieron en el pasado. En concreto, tanto los elementos más salientes de cada escultura -brazos, manos o piernas-, como los más delicados por su técnica de ejecución-vasos linfáticos, placentas, etc.-, han sido los más vulnerables a estos daños.

\section{Procesos de intervención}

Se han analizado las diferentes opciones y se ha desarrollado un plan de actuación basado en una serie de estudios previos cuyo corpus documental ha contribuido a construir el proceso de diagnosis de cada obra desde una interpretación crítica del estado de conservación, la determinación de problemas y sus posibles soluciones. Durante el proceso de intervención se ha contado con el asesoramiento de res- tauradores italianos especializados en ceroplástica y también se han recopilado informaciones concernientes a los tipos de materiales y a los métodos.

Los tratamientos de restauración han estado guiados por una constante actitud reflexiva basada en un permanente diálogo con cada obra a fin de encontrar alternativas para seleccionar el tratamiento más eficaz y alcanzar un equilibrio entre la intencionalidad del artista -en cuanto a los valores expresivos otorgados a la pieza escultórica-, la huella del tiempo sobre la materia y el disfrute estético del modelo anatómico. La elección de cada producto utilizado se ha hecho teniendo en cuenta los criterios habituales de estabilidad, compatibilidad y reversibilidad.

\section{A.- Fase de limpieza}

Se puso a punto un protocolo de actuación apoyado en una investigación bibliográfica y en test preliminares efectuados con lupa binocular. Se comenzó por una limpieza de las superficies delicadas de las ceras. La diversa tipología de las obras, la variedad de texturas y de acabados, junto al diferente estado de conservación, y el espesor de los depósitos de polvo, así como la cohesión de éstos a la superficie de las esculturas, han determinado la elección metodológica. Con un micro-aspirador, dotado de filtro para que los fragmentos céreos desprendidos no fuesen absorbidos, y brochas de pelo de pony, se han retirado los depósitos de polvo en suspensión; las zonas donde estas partículas estaban más adheridas han requerido de una 
puntual acción mecánica con instrumental específico. El cabello humano ha precisado una aspiración de las partículas contaminantes con la interposición de una tela de tul y el control tanto de la distancia como de la presión del aire [figura 1]. Las zonas más delicadas se han trabajado con ayuda de una pera de aire y se ha realizado una limpieza de los mechones -cubiertos de manera accidental por la película de barniz no original muy oxidada que los alteraba-, con papel absorbente empapado en alcohol desnaturalizado; se ha elegido este método dado que se trata de un material orgánico muy sensible a la humedad. El tratamiento ha concluido con la humectación de cada pelo con una máquina de vapor por ultrasonidos para aportar al conjunto la hidratación perdida.

La remoción de las sustancias contaminantes se ha hecho por medio de un ambiente acuoso. Se ha tenido en cuenta que la cera, al ser un material hidrófilo y situarse en la parte derecha del Triángulo de Solubilidad de Teas -elevado valor de Fd (fuerzas dispersivas), bajo valor de Fp (fuerzas polares) y de Fh (fuerzas de puente de hidrógeno)-, no se ve afectada por la acción de los disolventes muy polares, como es el caso del agua. Se midió el pH en la superficie de los modelos anatómicos y se comprobó la acidez alcanzada por el deterioro del estrato filmógeno de resina de colofonia, entorno a valores de 4,9-5. Por esta razón se consideró adecuado el uso de un tampón ácido con pH 5. Se incorporó 0,2 g de ácido acético (en solución acuosa al 80\%) a $100 \mathrm{ml}$ de agua desmineralizada. Se tamponó la mezcla a un $\mathrm{pH} 5$ con una solución de $\mathrm{NaOH} 1 \mathrm{M}$ y se añadió $0,2 \mathrm{~g}$ de citrato de triamonio, ajustando la conductividad a $4 \mathrm{mS} /$ cm para evitar causar posibles pasmados sobre la película de recubrimiento. La adición de éste último producto y el valor de conductividad señalado favorecieron la remoción de las partículas grasas de contaminación, ya que el citrato contribuye a disminuir la tensión superficial y en consecuencia mejora la capacidad humectante de la solución, sin causar interacción con los componentes originales de la obra. Donde no había estrato de material filmógeno, se subió el pH a 6 y se trabajó con una conductividad máxima de $5 \mathrm{mS} / \mathrm{cm}$.

En cuanto a la metodología, se ha humedecido la zona a limpiar con pequeños hisopos de algodón impregnados en la solución acuosa, haciéndolos rodar, con suavidad y en varias pasadas, hasta alcanzar el grado de limpieza deseado. En algunas zonas, donde se precisaba un mayor tiempo de acción de la solución en superficie, se ha extendido ésta con la ayuda de un pequeño pincel deslizado sobre una lámina de papel japonés o tisú [figura 2]. En los intersticios donde se había acumulado más suciedad y era difícil acceder, se ha optado por aplicar la solución con un pequeño pincel de cerdas suaves y tamponar a continuación con una gasa finísima de algodón. Es importante extremar las precauciones para evitar que la solución pudiese causar algún tipo de acción no deseada sobre las zonas de la escultura sin recubrimiento. Todo el proceso se ha realizado bajo un microscopio estereoscópico y se ha ajustado para alcanzar un nivel de compromiso.

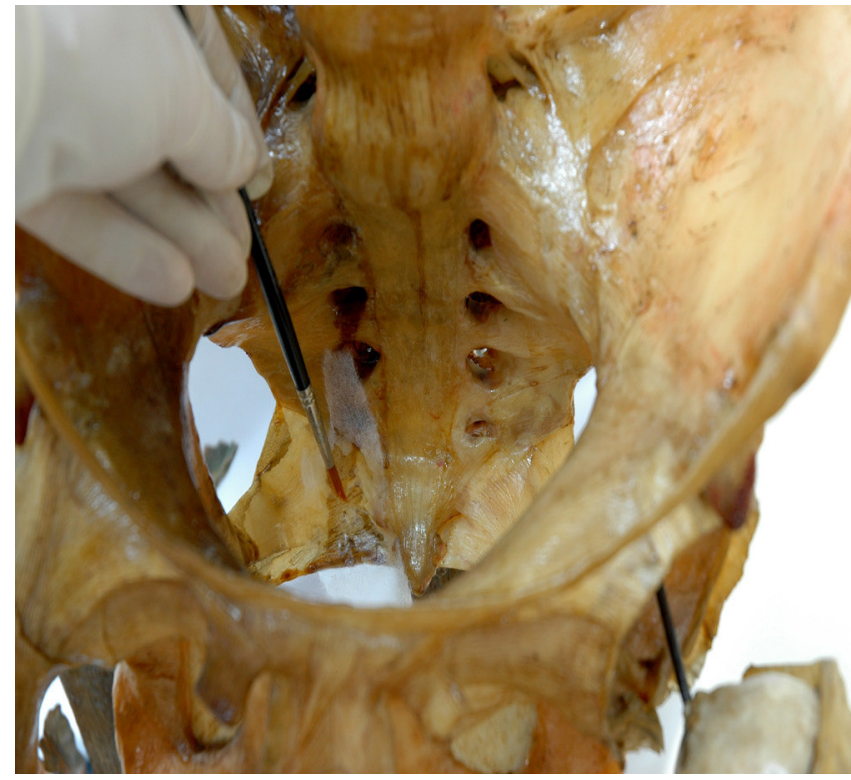

Figura 2. Proceso de limpieza por vía húmeda con solución tampón e interposición de una hoja de papel japonés. Detalle hueso de la pelvis en la figura del Esqueleto completo (MAJP000283). Cera, metal, madera policromada, papel. 77 × 64 × $174 \mathrm{~cm}$. $\odot$ Alicia Sánchez Ortiz.

Esta primera limpieza ha conseguido retirar de la superficie de las esculturas los estratos de suciedad pero, a la vez, ha acentuado el efecto negativo generado por la película de recubrimiento no original, al dejar al descubierto las desigualdades en el modo de aplicación de la misma, con zonas de las piezas sin cubrir de barniz frente a otras con aureolas, espesores irregulares y gotas de resina. Ésta, al envejecer, ha provocado aureolas parduzcas y amarillentas que transforman los valores cromáticos de los detalles anatómicos y otorga un aspecto plastificado a las superficies, alejado por completo de los acabados que imitaban las calidades aterciopeladas de la piel humana. Esta situación de deterioro que afectaba tanto a los valores estéticos como a la conservación material de las esculturas, llevó a valorar la opción de realizar una fase de limpieza más profunda que, está vez, sí actuase sobre el material filmógeno. Tras discutir posibles alternativas, se acordó con los diferentes actores implicados -Vicerrectorado de Extensión Universitaria, dirección técnica del Museo de Anatomía de la Facultad de Medicina y responsable de la restauración-, llevar a cabo el aligeramiento de estas capas con fuerte proceso de oxidación. Se eligió para ello un disolvente orgánico, el etanol absoluto PRS, al ser un alcohol caracterizado por un bajo contenido de agua, una alta polaridad (4,3 p), una acidez de 15,9 pKa y una rápida evaporación. Se trabajó extremando las precauciones con apoyo de microscopio, siempre actuando sobre áreas muy pequeñas, sólo en las partes de las esculturas cubiertas por los barnices y mediante la acción directa con hisopos rodados suavemente o sustituyendo a éstos -en caso de presentar la superficie micro-fisuras o un estado de mayor fragilidad-, por papetas de papel tisú y/o japonés - de diferentes gramajes-, impregnadas con pincel y trascurridos 


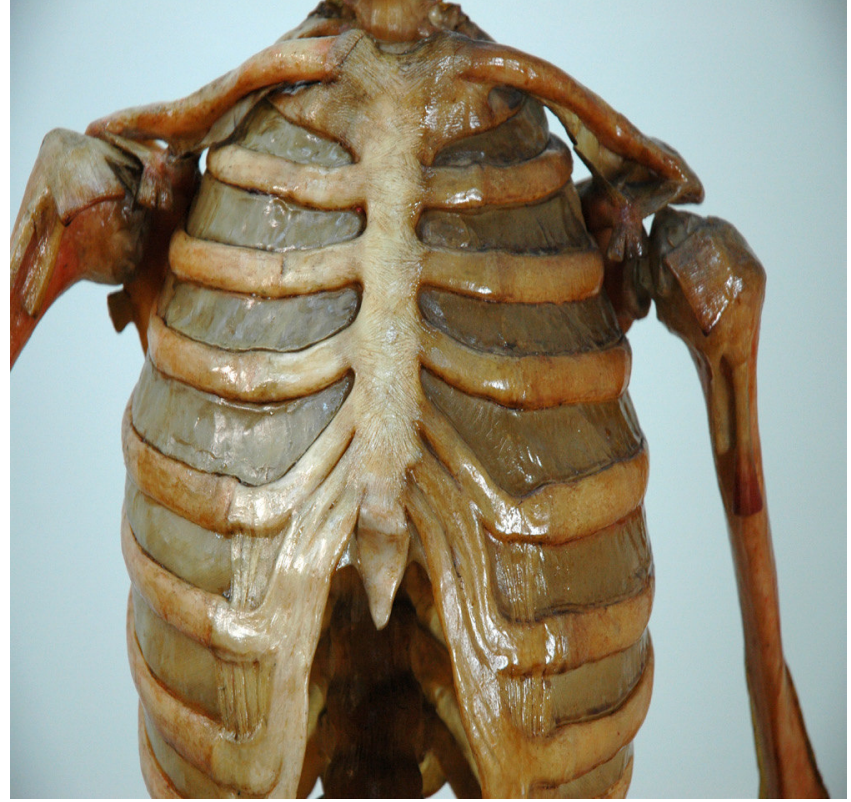

Figura 3. Aligeramiento de las capas de barniz no originales con disolvente orgánico. Detalle caja torácica Esqueleto completo. @Alicia Sánchez Ortiz.

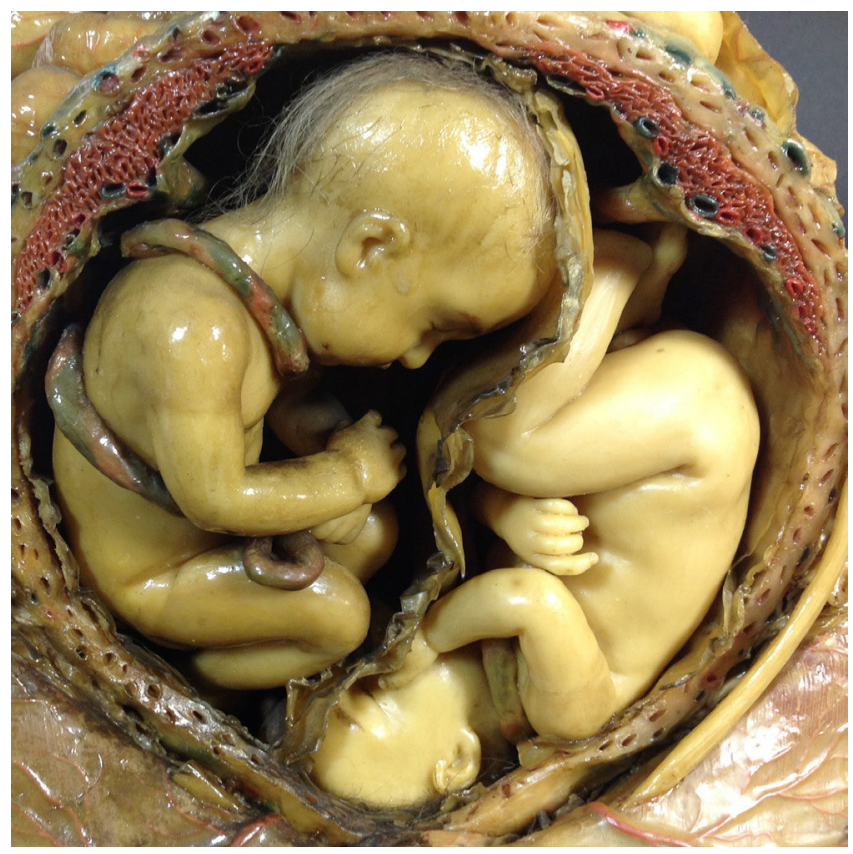

Figura 4. Detalle fase de limpieza: el feto de la izquierda muestra el estado inicial de conservación, con los depósitos de polvo y oxidación de la película de recubrimiento, y el de la derecha el resultado alcanzado con el aligeramiento de los mismos. Embarazo Gemelar (MAJP000137). Cera policromada, cabello humano, madera. 55 × 30 × 66 cm. @ Alicia Sánchez Ortiz.

unos minutos, retiradas con unas pinzas quirúrgicas. Esta limpieza se ha efectuado de manera gradual, con un escrupuloso control de los tiempos de evaporación y retención del disolvente, dejando endurecer la cera antes de llevar a cabo una nueva actuación sobre la misma zona. Se han empleado lámparas de fluorescencia ultravioleta y lupas binoculares para la valoración de los resultados. Al aligerar la película filmógena se ha conseguido mejorar la percepción de los volúmenes y de los detalles anatómicos, antes, ocultos bajo tonalidades parduzcas, además de recuperar un aspecto estético más acorde con la intencionalidad de los artífices [figuras 3 y 4].

\section{B.- Tratamiento de grietas, adhesión de fragmentos y relleno} de lagunas

Algunas de las esculturas tenían pequeñas pérdidas o falta de adhesión en determinados elementos anatómicos. Como norma general el tipo de adhesivo se ha elegido en función del tamaño de las piezas fragmentadas que precisaban tratamiento y de la resistencia mecánica a soportar. Se ha preferido optar por productos flexibles y con buen poder de adhesión.

En la figura Laparotomía media de mujer gestante, las lascas de cera desprendidas que rodean el feto -simulando la matriz de la madre-, se unieron al soporte con puntos de Lascaux ${ }^{\circledast}$ adhesivo cera 443-95. Se trabajó con microscopio para recolocar los pequeños fragmentos con la ayuda de pinzas quirúrgicas. Similar tratamiento requirieron las partes dañadas de las arterías y venas, próximas a la figura del embrión.

La escultura Embarazo Gemelar mostraba daños ocasionados por un golpe accidental con pérdida de materia en la sección del vientre materno izquierdo superior y desprendimiento de la zona inferior del pecho izquierdo. Se procedió a la separación de la parte dañada de manera mecánica, se limpiaron sus bordes con alcohol y se aplicó en ellos un acetato de polivinilo, tipo PVA, pincelado [figura 5]. Se introdujeron alfileres entomológicos, ligeramente calentados, para favorecer la colocación del fragmento en su

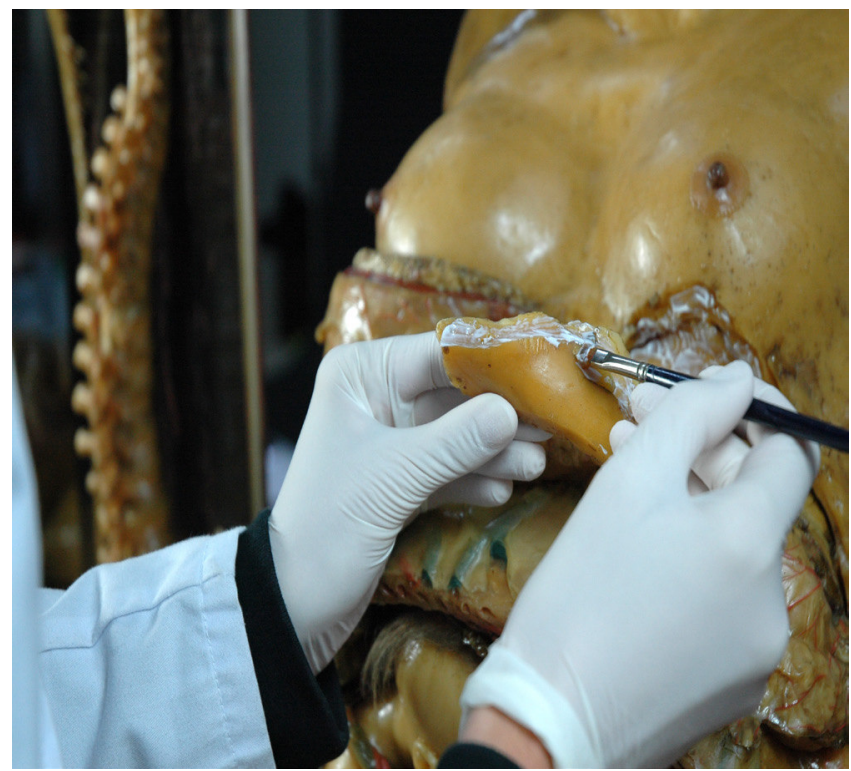

Figura 5. Adhesión del fragmento situado en la parte baja del seno derecho. Embarazo Gemelar. @Alicia Sánchez Ortiz. 
posición exacta y asegurar su sujeción final.

Elementos anatómicos como manos o pies tenían deterioros de diversa entidad. En el Esqueleto, la fragmentación de los dedos de ambas manos precisó de un delicado proceso de recomposición de las piezas y su posterior adhesión con la combinación de dos tipos de productos, Lascaux ${ }^{\circledast}$ adhesivo cera $443-95$ para unir los fragmentos de pequeño tamaño que debían soportar poco peso y PVA donde se requería encolar elementos sometidos a mayores tensiones mecánicas [figura 6]. Las uniones fueron mantenidas con una ligera presión mediante finas tiras de papel o tejido con micro-poros. El tronco del árbol, construido con madera policromada a la encáustica, tenía algunas grietas y para devolver la robustez a su estructura se humectó la zona a tratar con alcohol y a continuación se inyectó con jeringuillas Vinavil ${ }^{\circledR} 59$ diluido en agua destilada. Las escamas en la policromía se fijaron con la misma resina vinílica y se ejerció una ligera presión puntual hasta el secado completo del adhesivo.

La pérdida de adhesión de elementos delicados como los vasos linfáticos al conjunto de la estructura anatómica en Torso Drenaje Linfático, se trató con pequeños puntos de Lascaux ${ }^{\circledast}$ adhesivo cera 443-95, depositados con cuidado sobre el hilo de seda recubierto con cera que estaba desprendido y a continuación procediendo a su acomodo en la posición inicial mediante la ayuda de unas pinzas quirúrgicas y microscopio; fue necesaria una ligera presión temporal con sondas dentales [figura 6]. Se ha elegido éste porque una vez completada su polimerización, presenta un alto índice de transparencia, además de cierta flexibilidad, lo que contribuyó a facilitar la colocación de cada vaso en las concavidades originales. Para favorecer la manipulación y colocación de los hilos, se optó por

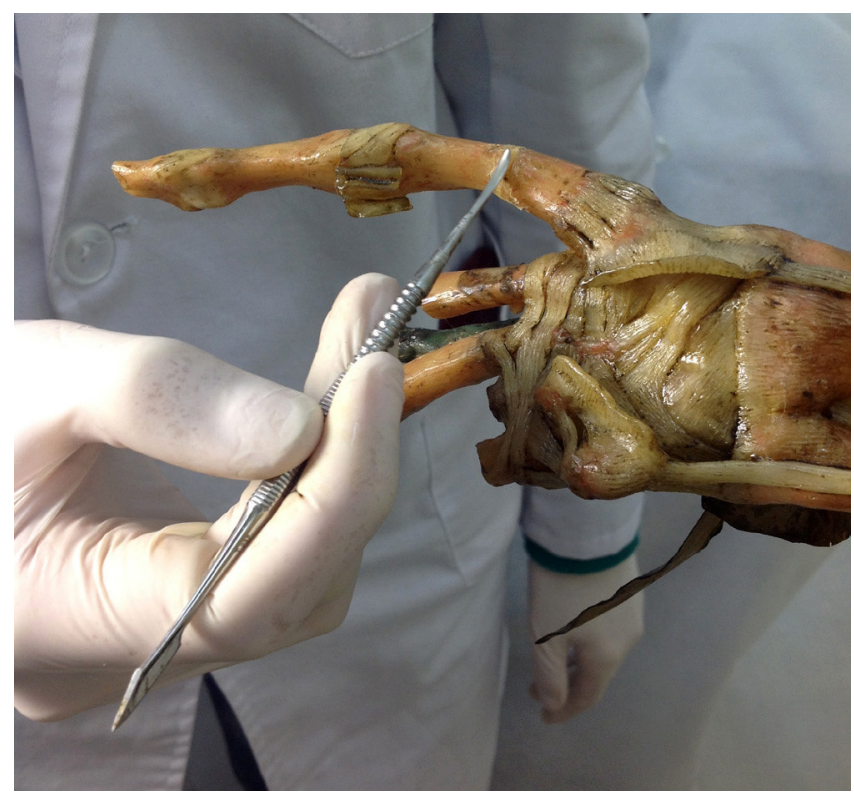

Figura 6. Proceso de recomposición y unión de los dedos de la mano izquierda desprendidos. Esqueleto completo. (c) Alicia Sánchez Ortiz.

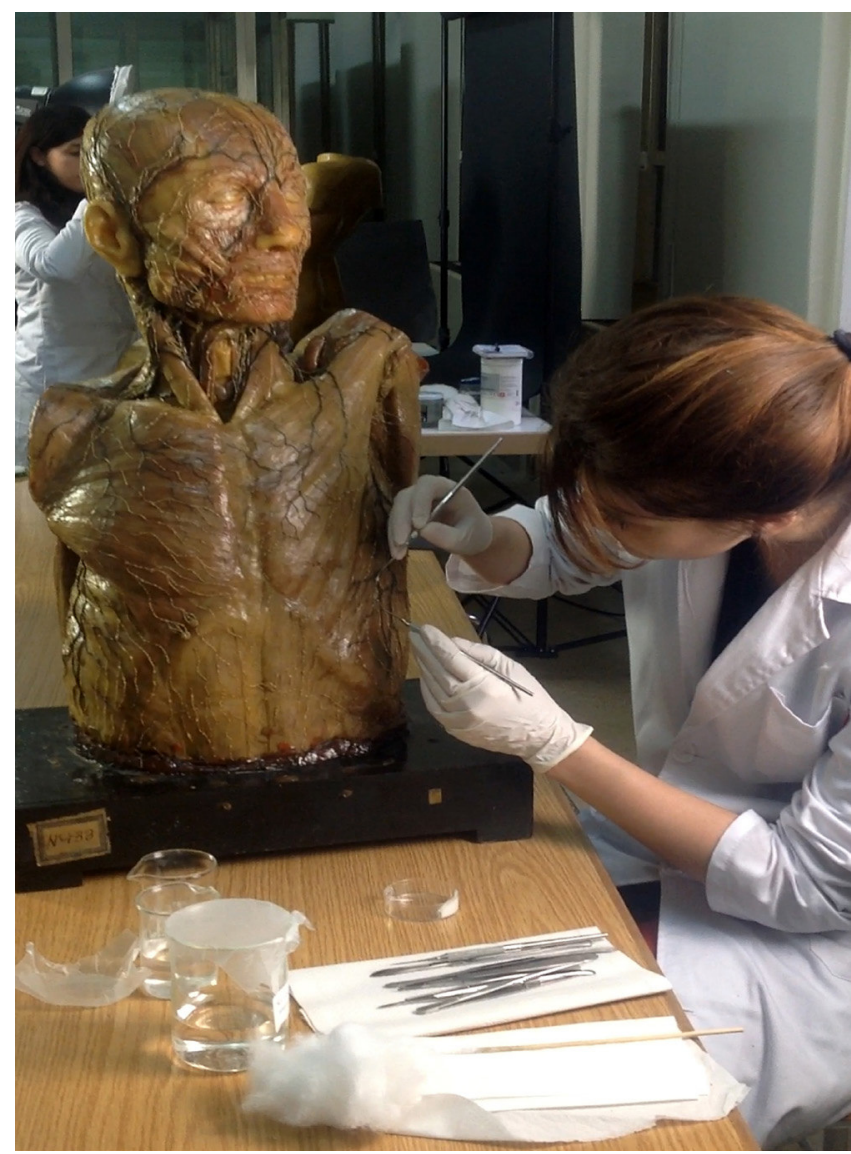

Figura 7. Fase de recolocación de los vasos linfáticos con puntos de adhesivo. Torso Drenaje Linfático (MAJP000171). Cera policromada, hilos de seda, madera. 40,5 × 26,5 x67 cm. @ Alicia Sánchez Ortiz.

adicionar unas gotas de alcohol al mismo, lo que ayudó a conseguir un mayor poder adhesivo en los primeros minutos.

Para recrear la unidad de la imagen y mejorar la comprensión de la obra, además de estabilizar la zona dañada, se consideró adecuado tratar las faltas matéricas con estratos sucesivos de una pasta constituida por una mezcla de Parafina 56/58 (1/3) y cera de abejas (2/3), preparada al baño María. Esta masilla de relleno fue aplicada en caliente, por goteo controlado, hasta rellenar los espacios huecos ocasionados por fragmentación o grietas [figuras 7 y 8]. Con instrumental específico -como escalpelos y la ayuda de lupas-, se fue retirando el exceso de ella sobre la superficie hasta lograr reestablecer una textura de continuidad con el original [figura 9].

\section{C.- Reintegración cromática}

Las zonas niveladas con la nueva pasta de cera se han reintegrado pictóricamente con acuarelas Winsor and Newton y pinceles de pelo de marta. Se ha elegido la técnica del puntillismo al permitir obtener una adecuada vibración tonal y se ha reconstruido la laguna con puntos de colores puros, yuxtapuestos y superpuestos en varias capas hasta 


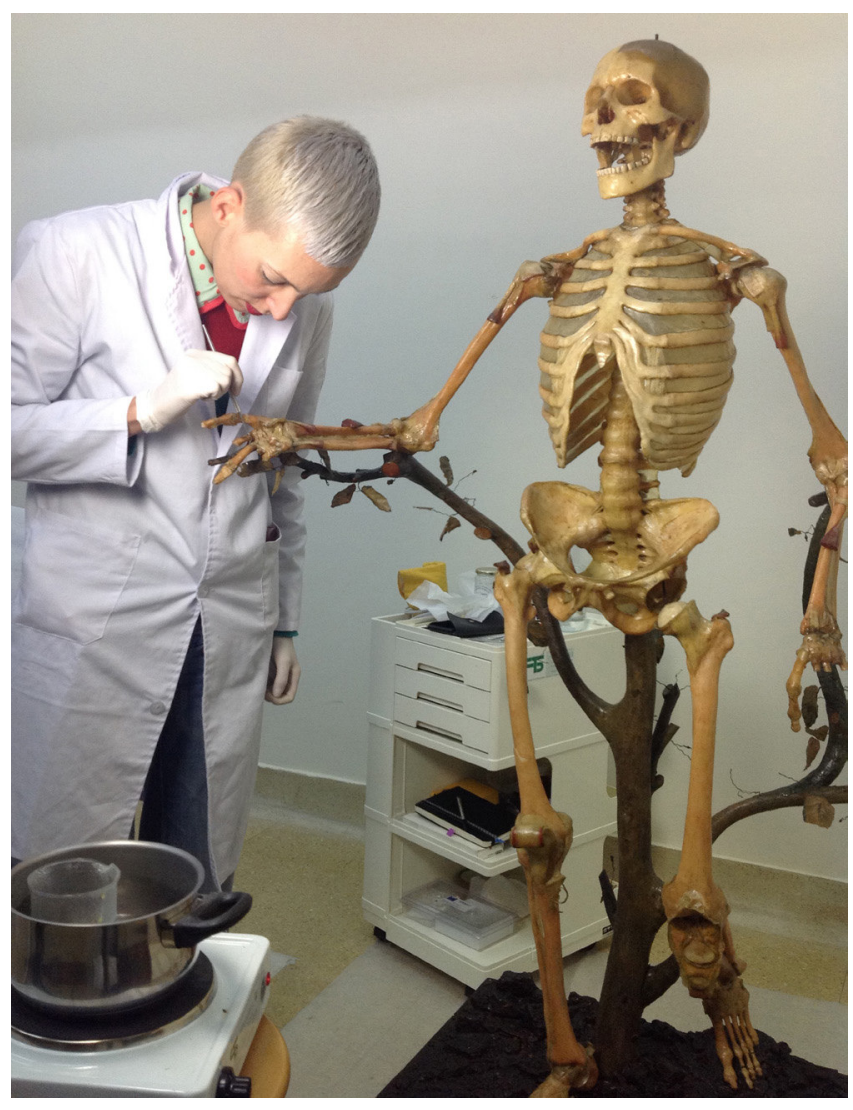

Figura 8. Tratamiento de nivelación de las faltas con pasta de cera en caliente. @ Alicia Sánchez Ortiz.

alcanzar la tonalidad del área original circundante [figura 10]. Se ha prestado atención al índice de refracción ya que es un factor esencial en el poder de opacidad que muestra un revestimiento pigmentado, como es el caso de las ceras. Se ha requerido de unas gotas de hiel de buey en el agua para reducir la tensión superficial durante el proceso. Los desgastes y pérdidas existentes en las peanas han sido retocados con pigmentos al barniz Maimeri ${ }^{\circledR}$ diluidos en Etil-L-Lactato, mediante veladuras.

\section{Acabados de protección}

Para otorgar una protección a la superficie de las esculturas, así como dotarlas de unos acabados diferenciados entre la opalescencia de la piel humana o el aspecto húmedo de los órganos blandos, se optó por aplicar, con brocha de pelo suave, una capa muy ligera de goma laca descerada decolorada diluida en alcohol anhidro. Se modificaron las concentraciones de la solución para obtener una variedad de calidades ópticas acordes con el elemento anatómico.

\section{Conclusiones}

El presente trabajo generó un debate crítico entre restauradores, técnicos de museos, historiadores del arte y anatomistas, en torno a la propuesta de tratamiento para las esculturas en cera objeto de este estudio. La recopila-

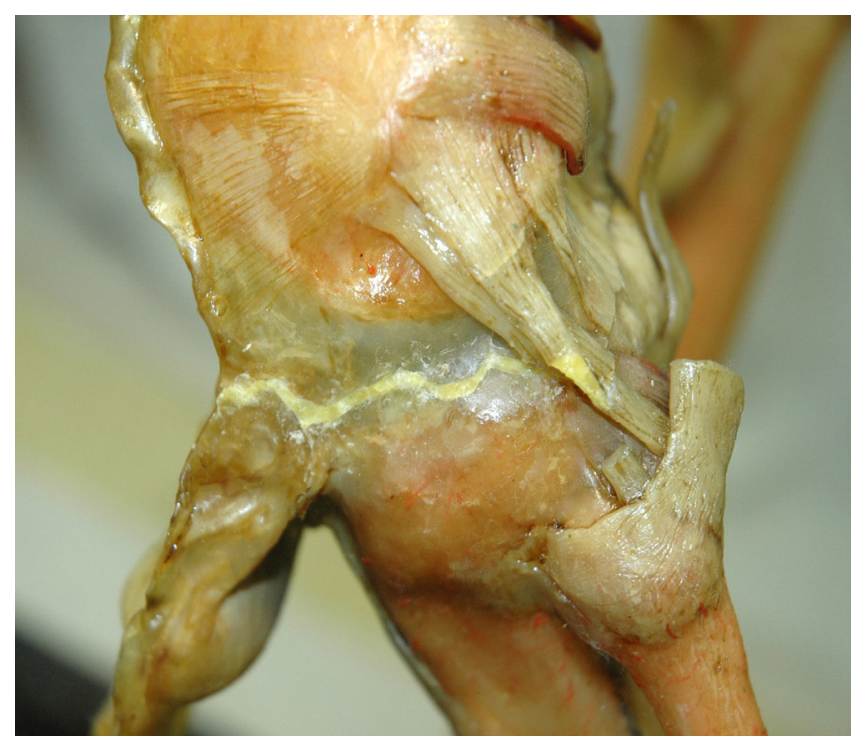

Figura 9. Detalle parte anatómica finalizado el enrasado mecánico de la pasta de relleno. Esqueleto completo. @ Alicia Sánchez Ortiz.

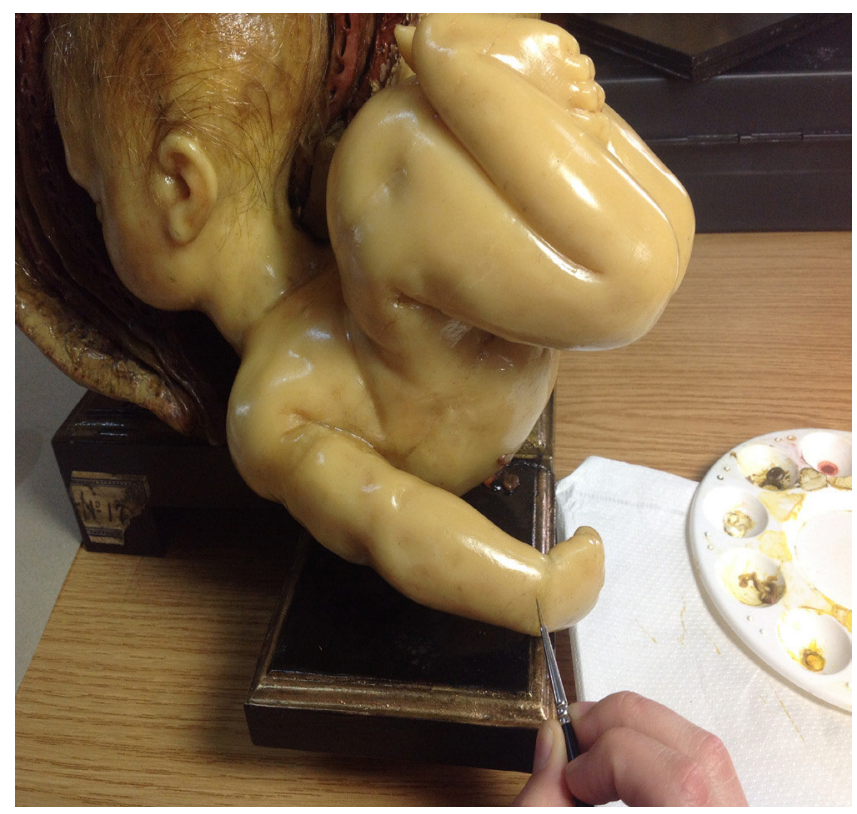

Figura 10. Reintegración cromática de las lagunas en la mano derecha del feto llevada a cabo con acuarelas y puntillismo. Parto podálico (MAJP000143). 43 × 38,5 x 39 cm. @ Alicia Sánchez Ortiz.

ción de documentación sobre los antecedentes históricos y el estado de conservación de las obras, la elaboración de fichas técnicas y de registros fotográficos, así como la observación al microscopio y su comparación con el resto de piezas de la colección, aportaron una información primordial. El conjunto de estos datos permitió reflexionar sobre las posibles alternativas y contribuyó a afrontar el tratamiento de restauración con rigor. La intervención se centró en estabilizar los procesos de degradación y en favorecer una mejor valoración de las calidades técnicas y artísticas de las esculturas.

Los modelos anatómicos en cera del Museo de Anatomía 
"Javier Puerta" son, sin duda, un claro exponente del rico patrimonio perteneciente a la Universidad Complutense. Estas obras, transmisoras directas de los avances en el saber, muestran, por medio de la plástica, los logros alcanzados en la investigación anatómica. Constituyen un importante legado de la historia de la medicina y son valiosos ejemplos del binomio entre arte y ciencia que acaeció en la época de la Ilustración. Las características señaladas convierten a esta colección en un ejemplo extraordinario dentro de nuestro patrimonio cultural, merecedora de continuar con la implementación de programas de conservación-restauración en el futuro.

\section{Agradecimientos}

El presente artículo se ha desarrollado en el marco de las investigaciones derivadas de la concesión, por parte del Ministerio de Ciencia e Innovación, del Proyecto de Investigación del Plan Nacional, referencia HAR2009-10679, así como dentro del Proyecto de colaboración con el Museo de la Evolución Humana de Burgos. La autora quiere expresar su reconocimiento al equipo de restauradoras, Nerea del Moral, Elena Rodríguez-González de Canales y Beatriz San Cristóbal, y su agradecimiento a las personas y empresas que, con su colaboración, han hecho posible este trabajo, en especial al profesor Fermín Viejo Tirado, en calidad de Director del Museo de Anatomía de la Facultad de Medicina, a Íñigo Larrauri de Terán, responsable de la Unidad de Gestión del Patrimonio Histórico de la UCM, y a Fabio Dal Monte, de CTS España.

\section{Bibliografía}

BERZIOLI, M. et al. (2010). Verificia analitica dell'idoneità delle soluzioni acquose nella pulitura di sculture in cera. Padua: II Prato. Quaderno Cesmar 7.

BESNAIOU, D. (1984). Cire et cires. Étude sur la composition, l'altération, la restauration, la conservation des oeuvres céroplastiques. París: Institut Français de Restauration des Oeuvres d'Art.

BUSCHENDORF, I. (1995). Keroplastik, geformtes Wachs. Unpublished diploma thesis. Stuttgart: State Academy of Art and Design.

CHAMPAGNAC, H. (2002). Étude e restauration de trois modèles de sculpture navale du XVIIle siècle en cire rouge. Musée national de la Marine, Paris. Recherches sur le nettoyage des œuvres en cire et cire patinée. Memoria de fin de estudios. Institut National du Patrimoine (INP IFROA), Saint Denis.

CHICOINEAU, L. (2001). “Les masques de chirugie maxillo-faciale en cire du Musée du Sal-de-Grâce". Conservation-restauration des Biens Culturels (CRBC), 17/18: 27-32.

CHICOINEAU, L. (1989). "Le nettoyage des objects de cire. Rapport résumé d'une recherche effectuée au Musée National des Arts et Traditions Populaires". Conservation-Restauration des
Biens Culturels (CRBC), 1: 22-25.

CORDUA, M.G.; LANTERNA, G.; LOMBARDI, L. (2009). "Mirabili orrori: Cere inedite di Gaetano Zumbo dopo il restauro". OPD Restauro, no 21: 71-87.

DAL FORNO, F. (2009). La ceroplastica anatomica e il suo restauro. Un nuovo uso della TAC, una possibile attribuzione a G. G. Zumbo. Firenze: Nardini.

DELCROIX, G. et al. (2005). Les cires: matériaux de sculpture, matériaux de restauration, Tours: Les rencontres de I'ARSET.

DERNOVSKOVA, J. (1997). "The use of propolis in seal conservation". SS CR Journal, vol.8 (2): 12-15.

ELLIS, S.; MILLER, C.; NOSEWORTHY, G. (1996). The conservation of wax model from a Medical Colllection. Twenty-second Annual AGPIC (Association of Graduate Programs in Art Conservation). Student Conference, April, 18-20. Kingston: Queen's University, pp.40-8.

FILIPP, M. (1998). Keroplastik: Herstellungstechniken, Schadensbilder und Klebung von gebrochenem Wachs. Unpublished diploma thesis. Erfurt: University of Applied Sciences.

FISCHER, A.; ESKA, M. (2011). "Joining broken Wax Fragments: testing tensile strength of Adhesives for fragile and no-polar substrates". Papers Ethnographic Session, 16 th Triennial Conference. ICOM 19-23 september. Lisboa, pp.

GABRRIELLINI, C.; NESI, G.; ROSSI, F.; SPERANZA, L. (2008). “Il restauro di un manufatto in cera del Museo di Anatomia Patologica di Firenze. Il busto di bambino idrocefalico eseguito da Luigi Calamai nel 1831". OPD Restauro, 20: 227-234.

GABBRIELLINI, C. et al. (2009). "La collezione di cere del Museo di Anatomia Patologica di Firenze. Note sulle vicende storiche, sulla técnica esecutiva e sui restauri". OPD Restauro, 21: 51-70.

GRAMTORP, D. et al. (2013). "Investigation and Conservation of Anne Marie Carl-Nielsen's Wax models". Studies in Conservation, vol.0: 1-10 (Consulta electronica)

HAVILAND, T. N.; PARSIH, L. C. (1970). "A brief account of the use of wax models in the study of medicine". Journal of the History of Medicine and Allied Sciences, 25 (1): 52-75.

HÜCKEL, A.; SCHNELL, I. (1987). "Examination and restoration of the votive wax figure of Anna Bruggmayr's in the Kreszentia monastery in Kaufbeuren". Zeitschrift für Kunsttechnologie und Konservierung, no 27 (Issue 1): 143-155.

KAUFMANN, V. (1998). "Restoration of an 18th Century Half Lifesize Anatomical Figure Modeled in Beeswax". The Conservator, 12: 25-30.

KÜHN, H. (2001). Conservation and restoration of works art and antiquities. London: Butterworths. 
LANG, J. (2011). "Adhesives for Wax Artifacts: Investigation of Suitable Materials and Their Adhesion Properties via Tensile and Bending Tests". Symposium Adhésives and Consolidants for Conservation. Research and Application, (17-21 october). Canada: CCI Symposium ICC-Ottawa, (http://www.cci-icc.gc.ca/discoverccidecouvriricc/PDFs/Paper\%208\%20-\%20Lang\%20-\%20English. pdf)

LAPKIN, R. et al. (2002). "Waxing Scientific: Exploring New Options for Wax Seal Consolidation". The Book and Paper Group Annual 21: 95-98.

LEGENDRE, S. (2001). Esquisse en cire pour un tombeau d'évêque fin du XIX, debut du XX siècle attribuée à François Sicard, Musée des Beaux-Arts de Tours: étude et restauration, Mèmoire de fin d'Études. Tours: École Supérieur des Beaux-Arts de Tours.
MURRELL, J. (1971). "Some aspects of the conservation of wax models". Studies in Conservation, 16: 95-109.

PRADIER, I. (2011). A corps ouvert: etude et restauration d'une cire anatomique Florentine de la fin du XVIII siècle (Conservation d'Anatomie de Montpellier). Recherche sur les máteriaux de comblement des objets en cire. Mémoire de fin d'Étude. París: Institut National du Patrimoine (INP).

REIFARTH, N. (2003). “Das Phänomen der Schichtentrennung an Wachsumhüllungen mittelalterlicher Altarreliquiare". Zeitschrift für Kunsttechnologie und Konservierung 16 (2): 340-356.

REIFARTH, N. (2004). "Polyethyenglycol und Propolis zur Konservierung brüchiger Wachsobjekte". Breiträge, Zur Erhaltung von Kunst und Kulturgut Verband der Restauratoren, Helf 2.

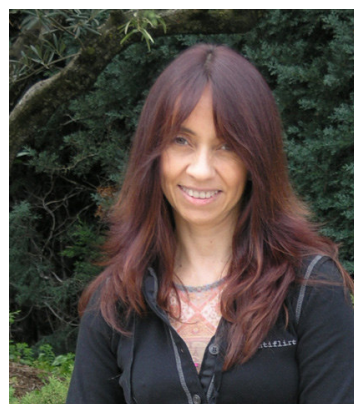

\author{
Alicia Sánchez Ortiz \\ Profesora Titular de la Facultad de Bellas Artes \\ Universidad Complutense de Madrid. C/Greco 2, 28040 \\ alicisan@ucm.es
}

Imparte desde el año 1993 docencia en la Facultad de Bellas Artes, dentro del Departamento de Pintura y Restauración, en las diversas titulaciones relacionadas con la Conservación y Restauración del Patrimonio Cultural. Pertenece al Grupo de Investigación cromática: aspectos técnicos, formales y de significado en la expresión del color a través del arte (UCM-930735). Ha realizado estancias en el Istituto Centrale del Restauro de Roma, en el Museo Nacional del Prado y en la Facultad de Xalapa, en México. Ha sido Directora del Magister en Conservación y Restauración de Arte Contemporáneo, impartido entre la Universidad Complutense y el Museo Nacional Centro de Arte Reina Sofía. Miembro del Grupo de Conservación-Restauración del IAC (Instituto de Arte Contemporáneo). Ha dirigido y formado parte de varios proyectos I+D relacionados con la conservación del patrimonio científico-artístico, destacando El arte de la ceroplástica anatómica: caracterización de materiales y metodología de actuación en conservación de colecciones de modelos anatómicos en cera (HAR200910679) y La ceroplástica en veterinaria: documentación, caracterización de materiales y métodos de conservación-restauración en la colección Complutense (HAR2013-42460-P). Conferenciante y ponente en congresos nacionales e internacionales dentro del campo del color y de la conservación del Patrimonio. Ha escrito capítulos de libros, catálogos, actas de congresos y publicado artículos de investigación en numerosas revistas. Es autora del libro Restauración de Obras de Arte: Pintura de Caballete, Madrid: Akal, 2012.

Artículo enviado el 17/02/2015

Artículo aceptado el 05/05/2015 